\title{
Çinko Oranının Al-(5-50)Zn Alaşımlarının Yapısal ve Mekanik Özelliklerine Etkisi
}

\author{
Effect of Zinc Content on the Microstructure and Mechanical Properties of the Al-(5-50)Zn \\ Alloys
}

Ali Paşa HEKIMOĞLU*,a, Yunus Emre TURAN ${ }^{b}$

Recep Tayyip Erdoğan Üniversitesi, Mühendislik Fakültesi, Makine Mühendisliği Bölümü, 53100, Rize

• Geliș tarihi / Received: 19.01.2018 • Düzeltilerek geliş tarihi / Received in revised form: 14.04.2018 • Kabul tarihi / Accepted: 01.06 .2018

\begin{abstract}
$\ddot{O} z$
Bu çalışmada ağırlıkça \%5 ile 50 arasında farklı oranlarda çinko içeren on adet ikili alüminyum-çinko alaşımı kokil kalıba döküm yöntemiyle üretildi. Üretilen alaşımların içyapıları ışık mikroskobunda incelendi. Alaşımların içyapısında bulunan fazları belirlemek için X-ışını kırınım (XRD) çalışmaları yapıldı. Elde edilen bulgular \% 15 çinko oranına kadar alaşımların içyapısının alüminyumca zengin $\alpha$ fazından oluştuğunu ve alaşımdaki çinkonun bu faz içinde tamamen çözündüğünü göstermektedir. Çinko oranı \% 15'i aştı̆ıında $\alpha$ fazının yanı sıra yapıda çinkoca zengin $\eta$ fazının oluşmaya başladığı, \%25'i aşması durumunda ise $\alpha$ fazının dendritik bir şekilde büyüdüğü görüldü. Alaşımların sertlik değerlerinin artan çinko oranı ile sürekli arttı̆̆ı, çekme ve basma dayanımı değerlerinin ise \%30 çinko oranına kadar arttığı bu orandan sonra azaldığı görüldü. Artan çinko oranı ile alaşımların içyapısında meydana gelen değişimler katılaşma davranışlarına, mekanik özelliklerinde meydana gelen değişimler ise yapısal değişimlere dayandırılarak irdelendi.
\end{abstract}

Anahtar kelimeler: Al-Zn Alaşımları, İçyapı, Mekanik Özellikler, Özgül Mukavemet

\begin{abstract}
In this study, ten binary aluminum-zinc alloys containing zinc in different ratios between 5 and $50 \%$ by weight were produced by permanent mold casting method. The microstructures of the produced alloys were examined in light microscope. X-ray diffraction (XRD) studies were carried out to determine the phases in the microstructure of the alloys. The findings show that the microstructure of the alloys up to $15 \%$ zinc is composed of aluminum-rich $\alpha$ phase and the zinc in the alloy completely dissolves in this phase. It was also showed that when the zinc content exceeds $15 \%$, besides the $\alpha$-phase, the zinc-rich $\eta$ phase begins to form, and when the zinc content exceeds $25 \%$, the $\alpha$-phase grows dendritically. The hardness, tensile, and compression strength values of the alloys increased continuously with increasing zinc content but after the \% 30 zinc content tensile and compression strength values decreased. The changes in the microstructure and mechanical properties of the alloys were discussed based on their solidification behaviors and structural changes.
\end{abstract}

Keywords: Al-Zn Alloys, Microstructure, Mechanical Properties, Specific Strength

\footnotetext{
*aa Ali Paşa HEKIMMOĞLU; ali.hekimoglu@erdogan.edu.tr; Tel: (464) 22375 18; orcid.org/0000-0003-2396-4876

${ }^{\mathrm{b}}$ orcid.org/0000-0002-2229-907X
} 


\section{Giriş}

Alüminyum esaslı alaşımlar üretimlerinin kolay ve ekonomik olmasının yanı sıra üstün yapısal, fiziksel, mekanik ve tribolojik özellikleri nedeniyle 19. yüzy1ldan itibaren makine, otomotiv, inşaat ve elektrik sanayilerinde yapılan imalatlarda önemli bir yer tutmuştur (ASM International Handbook Committee, 1992; Altenpohl, 1998; Kaufman ve Rooy, 2004; Dursun ve Soutis, 2014). Söz konusu alaşımların belirtilen özellikleri kimyasal bileşimlerine bir başka deyişle alaşım elementleri ve alaşım elementlerinin oranına göre farkl11k göstermektedir (Hatch, 1984; Gervais vd., 1985; ASM International Handbook Committee, 1992; Altenpohl, 1998; Murthy, 2003; Kaufman ve Rooy, 2004; Dursun ve Soutis, 2014). Bu nedenle alüminyum esaslı alaşımların kullanım alanı belirlenirken alaşım elementleri ve bu elementlerinin içyapıdaki oranları göz önüne alınarak karar verilmektedir. Alüminyum esasl1 alaşımlarda kullanılan alaşım elementlerinin başında bakır, magnezyum, mangan, silisyum, lityum ve çinko gelmektedir (ASM International Handbook Committee, 1992; Shabestari ve Moemeni, 2004; Wanga vd., 2016; Alhawari vd., 2017). Bunlardan bakır, mangan, silisyum, magnezyum ve lityum söz konusu alaşımların sertlik ve/veya mukavemetlerini artırmakta ancak süneklik değerlerini ise genellikle azaltmaktadır (ASM International Handbook Committee, 1992; Valiev vd., 2002; Lloyd, 2003; Alemdağ ve Beder, 2015; Lee vd., 2016; Savaşkan ve Hekimoğlu, 2016; Remøea vd., 2017). Çinko ise alüminyum alaşımlarının sertlik, mukavemet, tribolojik ve işlenebilirlik özelliklerinin yanı sıra yüzey kalitesini de iyileştirmektedir (Savaşkan vd., 1988; ASM International Handbook Committee, 1992; Savaşkan vd., 2009; Alemdağ ve Beder, 2014; Savaşkan ve Hekimoğlu, 2014a; Savaşkan ve Hekimoğlu, 2014b; Bayraktar vd., 2017a; Bayraktar vd., 2017b).

Alüminyum-çinko alaşımlarının yapısal ve mekanik özellikleri içyapılarını oluşturan fazlara bağlı olarak değişmektedir (Savaşkan vd., 1988; Savaşkan vd., 2009; Alemdağ ve Beder, 2014; Savaşkan ve Hekimoğlu, 2014a; Savaşkan ve Hekimoğlu, 2014b; Alemdağ ve Beder, 2015; Savaşkan ve Hekimoğlu, 2016). Bu nedenle alüminyum-çinko ikili ve alüminyum-çinko esasl1 çoklu alaşımların tasarımında ilk olarak Şekil 1'de verilen ikili alüminyum-çinko faz (denge) diyagramı (Auer ve Mann, 1936; Presnyakov vd., 1961; Kuznetsov vd., 1986) göz önüne alınmaktadır. $\mathrm{Bu}$ diyagramda artan çinko oranıyla çinkonun alüminyum içerisindeki katı çözünürlüğünün $\% 83$ oranına kadar ulaşabildiği ve sistemde farklı çinko oranlarında monotektoid, peritektik, ötektoid ve ötektik faz dönüşümlerinin meydana geldiği görülmektedir (Auer ve Mann, 1936; Presnyakov vd., 1961; Kuznetsov vd., 1986). Söz konusu alaşımların içyapısı ve mekanik özellikleri alaşımların katılaşmaları sirasinda bu dönüşümlerden hangisinin meydana geldiğine göre bir başka deyişle alaşımın çinko oranına göre farklılık göstermektedir (Savaşkan vd., 2003; Savaşkan vd., 2004; Savaşkan ve Hekimoğlu, 2014b).

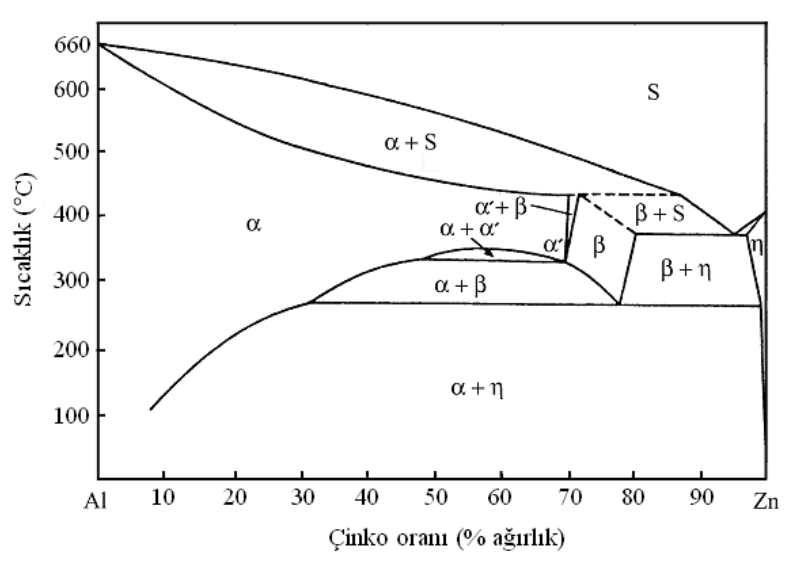

Şekil 1. İkili çinko-alüminyum faz diyagramı (Auer ve Mann, 1936; Presnyakov vd., 1961; Kuznetsov vd., 1986)

Üçlü veya daha çoklu alaşımlara baz belirlemek için ikili alüminyum-çinko alaşımları üzerinde en uygun çinko oranının belirlenmesine yönelik olarak farklı koşullarda çalışmalarda (Savaşkan vd., 2004; Savaşkan vd., 2009; Savaşkan ve Hekimoğlu, 2014b) belli oranlardaki çinko katkılarının sertlik ve mukavemet özelliklerine etkisi incelenmiştir. Ancak bu çalışmalarda \% 550 aralığında artan çinko oranı ile ikili Al-Zn alaşımlarında meydana gelen yapısal değişimler ve bu değişimlerin alaşım özelliklerine ve özgül mukavemetine etkisi yeterince detaylı bir şekilde incelenmemiştir. $\mathrm{Bu}$ nedenle bu çalışmada artan çinko oranı ile Al-(5-50)Zn alaşımlarında meydana gelen yapısal değişimler incelenerek bu değişimlerin alaşımın mekanik özelliklerine ve özgül mukavemet değerlerine etkisinin ortaya koyulması amaçlanmıştır.

\section{Deneysel Çalışma}

$\mathrm{Bu}$ çalışma kapsamında nominal kimyasal bileşimleri Tablo 1'de verilen on adet ikili alüminyum-çinko alaşımı döküm yoluyla üretildi. Alaşımların üretiminde ticari saflıkta $(\% 99,80)$ 
alüminyum ve yüksek saflıkta $(\% 99,9)$ çinko kullanıldı. Uygun kimyasal bileşimi elde edecek miktarlarda belirlenen alaşım elementleri bir indüksiyonlu ergitme ocağı içerisinde ergitilerek karıştırıldı. Sıvı durumdaki alaşımlar kimyasal bileşimlerine göre ikili Al-Zn faz diyagramındaki (Auer ve Mann, 1936; Presnyakov vd., 1961; Kuznetsov vd., 1986) ergime sicaklıkları göz önüne alınarak belirlenen döküm sıcaklıklarından (650-700 $\left.{ }^{\circ} \mathrm{C}\right)$, teknik resmi Şekil 2a'da verilen ve oda sicaklığında tutulan SAE 8620 çeliğinden üretilmiş olan bir kalıba dökülerek katılaştırıldı. $\mathrm{Bu}$ kalıptan elde edilen alaşım külçesinin teknik resmi Şekil 2b'de verilmiştir.

Tablo 1. Alaşımların nominal kimyasal bileşimleri

\begin{tabular}{lll}
\hline \multirow{2}{*}{ Alaşım } & \multicolumn{2}{l}{ A ğırlıkça element oranları (\%) } \\
\cline { 2 - 3 } & Çinko & Alüminyum \\
\hline Al-5Zn & 5 & Kalan \\
\hline Al-10Zn & 10 & Kalan \\
\hline Al-15Zn & 15 & Kalan \\
\hline Al-20Zn & 20 & Kalan \\
\hline Al-25Zn & 25 & Kalan \\
\hline Al-30Zn & 30 & Kalan \\
\hline Al-35Zn & 35 & Kalan \\
\hline Al-40Zn & 40 & Kalan \\
\hline Al-45Zn & 45 & Kalan \\
\hline Al-50Zn & 50 & Kalan \\
\hline
\end{tabular}

Metalografik incelemeler ile yoğunluk, sertlik, çekme ve basma değerlerinin belirlenebilmesi için gerekli numuneler Şekil 2b'de teknik resmi verilen alaşım külçelerinden talaşlı imalat yöntemiyle hazırlandı. $\mathrm{Bu}$ numunelerin teknik resimleri Şekil 3'de verilmiştir.

İçyap1 incelemeleri için Şekil 3a'da teknik resmi verilen numuneler standart metalografik yöntemlerle hazırlandıktan sonra \%2-4 oranında hidroklorik asit $(\mathrm{HCl})$ içeren saf $\mathrm{su}+\mathrm{HCl}$ ayıracı ile dağlandı. Dağlanmış durumdaki numuneler 1ş1k mikroskobunda incelendi ve alaşımların içyapılarını gösteren fotoğraflar çekildi. Çinko oranındaki değişime bağlı olarak alaşımların yapısında meydana gelen faz değişimleri metalografik gözlemlerin yanı sıra X-1şını kırınımı (XRD) yöntemi ile de incelendi. XRD çalışmaları $1 \%$ dk tarama hızında $\mathrm{Cu}-\mathrm{K} \alpha$ radyasyonu kullanılarak gerçekleştirildi. Alaşımların yoğunlukları numunelerin ölçülen kütle değerlerinin hesaplanan hacim değerlerine bölünmesiyle belirlendi. Kütle ölçümlerinde \pm 0.01 mg hassasiyetinde terazi, boyut ölçümlerinde ise dijital bir mikrometre kullanıldı. Sertlik ölçümleri 62.5 kgf yük ve $2.5 \mathrm{~mm}$ çapında uç kullanılmak suretiyle Brinell Sertlik Ölçüm Yöntemiyle gerçekleştirildi. Her bir alaşım için en az 6 ölçüm yapıld1 ve sonuçların ortalaması alınarak alaşımların yoğunluk ve sertlik değerleri belirlendi. Çekme ve basma deneyleri TS 138 ve TS 206 standartlarına göre teknik resimleri sırasıyla Şekil $3 \mathrm{~b}$ ve c'de verilen alaşım numuneleri ile ortalama $10^{-3} \mathrm{~s}^{-1}$ deformasyon hızında gerçekleştirildi. Her bir alaşım için en az altı adet çekme ve basma deneyi yapıldı. Alaşımların çekme dayanımı, kopma uzaması ve basma dayanımı değerleri bu deneylerden elde edilen sonuçların ortalamasının alınmasıyla, özgül mukavemet değerleri ise çekme dayanımı değerlerinin yoğunluk değerlerine bölünmesiyle belirlendi.

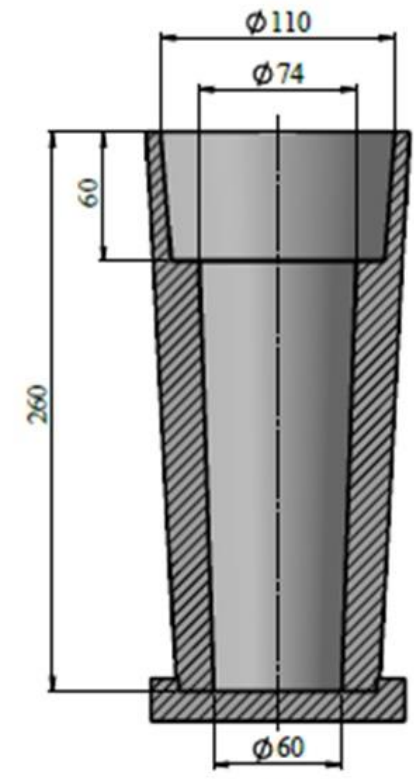

(a)

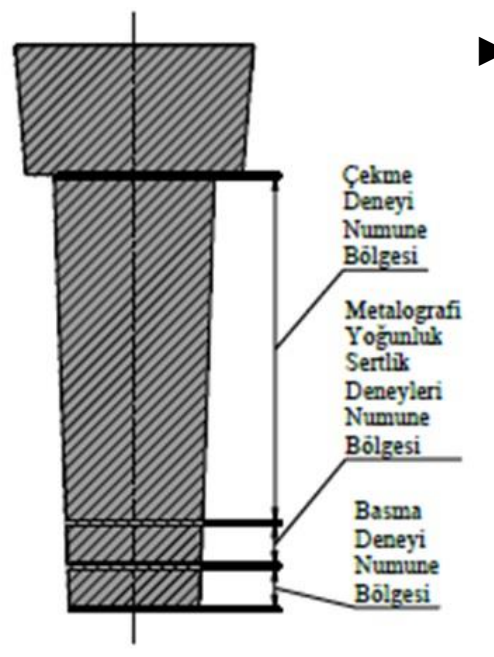

(b)

\author{
Şekil 2. (a) Alaşımların \\ üretiminde kullanılan \\ kokil kalıbın. (b) \\ Üretilen alaşım \\ külçelerinin teknik resmi
}




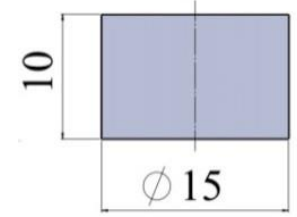

(a)

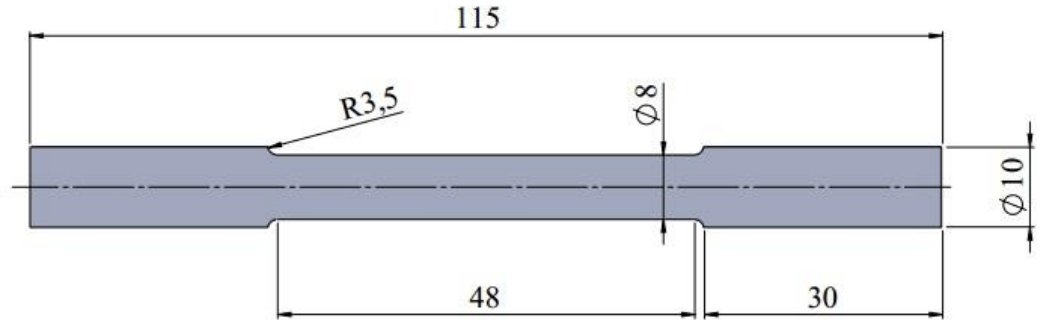

(b)

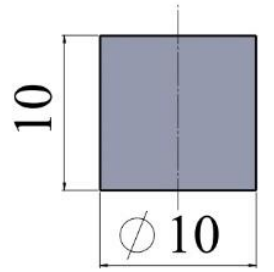

(c)

Şekil 3. (a) Metalografi, yoğunluk ve sertlik. (b) çekme ve (c) basma deneyi numunelerinin teknik resmi

\section{Bulgular ve Tartışma}

Üretilen alaşımların içyapısı ve içyapısındaki fazların belirlenmesi için yapılan çalışmalardan elde edilen 1şık mikroskobu görüntüleri Şekil 4'te, $\mathrm{X}$-ışını kırınım desenleri ise Şekil 5'de verilmiştir. $\mathrm{Bu}$ görüntüler alaşımların içyapısının \%15 çinko oranına kadar sadece $\alpha$ fazından oluştuğunu göstermektedir, (Şekil 4a-b). Çinkonun bu oranı aşması durumunda ise alaşımların içyapısında $\alpha$ fazının yanı sıra $\eta$ fazının oluştuğu ve artan çinko oranı ile $\eta$ fazının hacimsel oranının arttığ görülmektedir, (Şekil 4c-g). X-1şını kırınım desenleri de üretilen alaşımların içyapısında \%15 $\mathrm{Zn}$ oranına kadar sadece $\alpha$ fazına ait piklerin oluştuğunu (Şekil 5a ve b), bu çinko oranından sonra ise $\alpha$ fazının yanı sıra $\eta$ fazının oluşmaya başladığını ve çinko oranı arttıkça bu faza ait piklerin yoğunluğunun arttı̆̆ını göstermektedir, (Şekil 5c-g).

İkili alüminyum-çinko alaşımlarının içyapısında bulunan fazların oluşumu bu alaşım sistemine ait faz diyagramı ve dökümleri sonrasındaki katılaşma davranışına dayanılarak açıklanabilir. Şöyle ki, ikili faz (denge) diyagramına (Auer ve Mann, 1936; Presnyakov vd., 1961; Kuznetsov vd., 1986) göre alüminyum ve çinko sıvı durumda birbiri içersinde her oranda tamamen, katı durumda ise kısmen çözünmektedir. $\mathrm{Bu}$ kısmi çözünürlük nedeniyle ikili $\mathrm{Zn}-\mathrm{Al}$ alaşımları çinkonun alüminyum içinde çözünmesiyle oluşan $\alpha$ ve alüminyumun çinko içinde çok az da olsa çözünmesiyle oluşan $\eta$ fazlarından oluşan iki fazlı bir içyap1 sergilemektedir (Auer ve Mann, 1936; Presnyakov vd., 1961; Kuznetsov vd., 1986). Siv1 durumdan bu katı fazların oluşması alaşımın kimyasal bileşimine göre farkl11ık göstermektedir. Şöyle ki; çinko oranının \% 5 ile 30 arasında olması durumunda sıvı alaşım sırasıyla $\alpha+\mathrm{s}, \alpha$ ve $\alpha+\eta$ fazlarına dönüşerek katılaşmaktadır. Çinko oranının \%30 ile 50 aralığında olması durumunda ise farklı olarak $\alpha$ fazı $\alpha+\eta$ fazlarına dönüşmeden önce $\alpha+\beta$ fazlarına dönüșmektedir (Auer ve Mann, 1936; Presnyakov vd., 1961; Kuznetsov vd., 1986). Bu çalışma kapsamında incelenen $\mathrm{Al}-\mathrm{Zn}$ alaşımlarının içyapılarında \%15 çinko oranına kadar denge diyagramından farklı olarak sadece $\alpha$ fazının gözlenmesi $\alpha \rightarrow \alpha+\eta$ faz dönüşümün gerçekleşmediğini, bir başka deyişle $\alpha$ fazının içinde çözünmüş durumda bulunan çinko atomlarının bu fazdan ayrılıp çinkoca zengin $\eta$ fazını oluşturamadığını göstermektedir (Şekil 4a,b ve $5 a, b)$. 

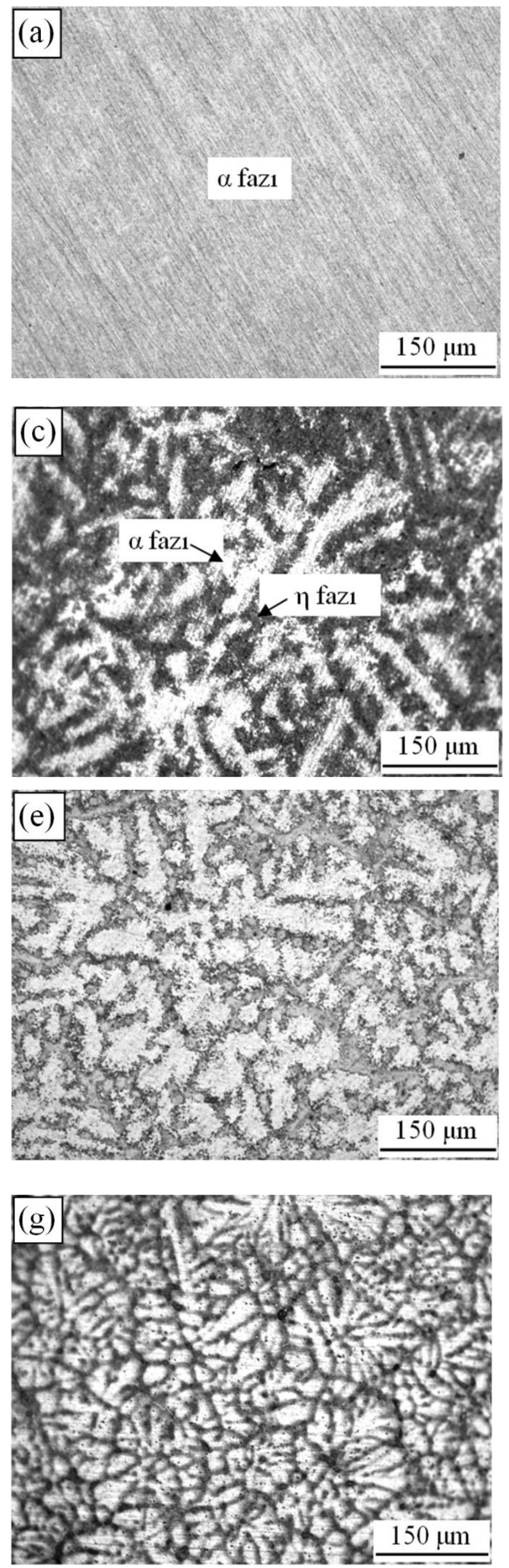
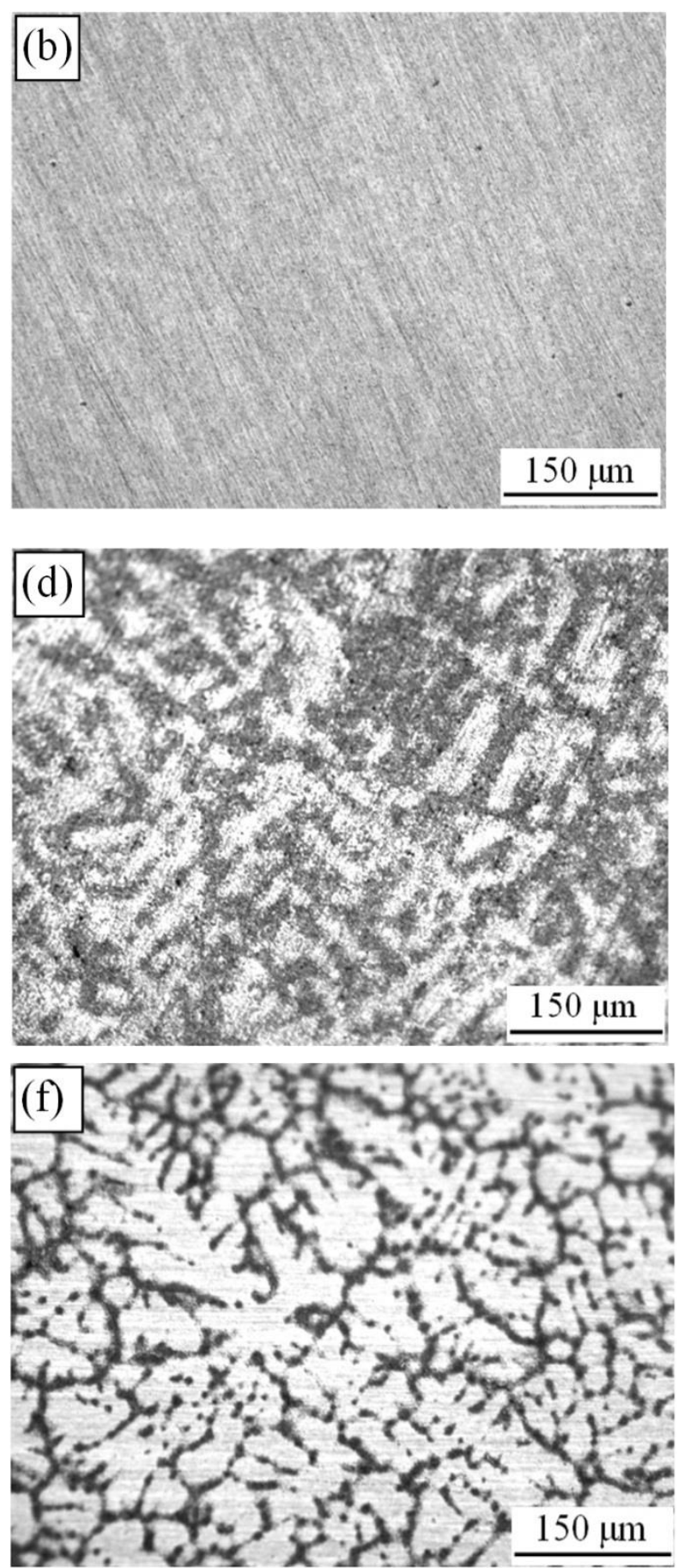

Şekil 4. (a) Al-5Zn, (b) Al-15Zn, (c) Al-20Zn, (d) $\mathrm{Al}-25 \mathrm{Zn}$, (e) Al-30Zn, (f) Al-40Zn ve (g) Al-50Zn alaşımlarının içyapısını gösteren fotoğraflar 

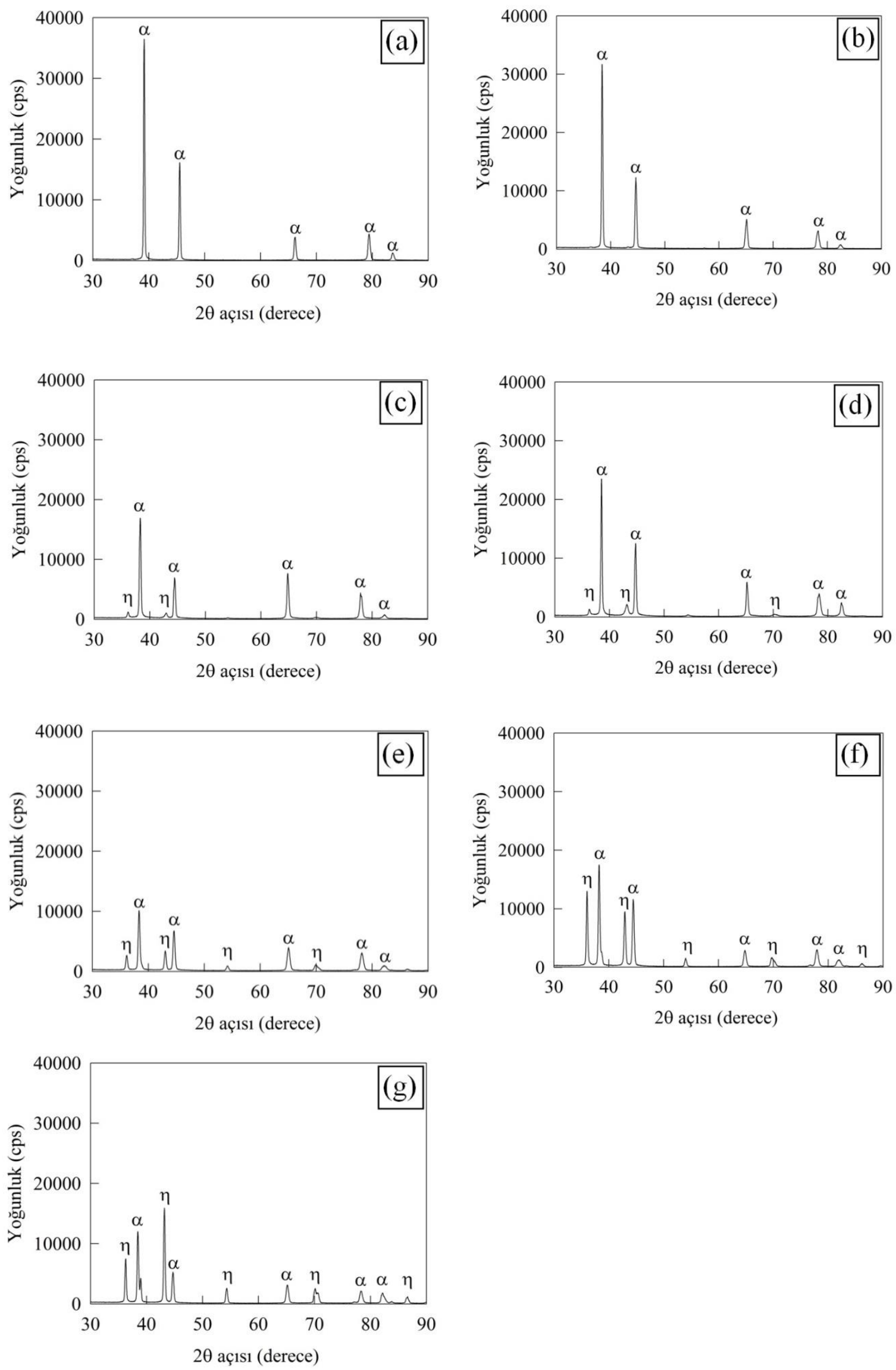

Şekil 5. (a) Al-5Zn, (b) Al-15Zn, (c) $\mathrm{Al}-20 \mathrm{Zn}$, (d) $\mathrm{Al}-25 \mathrm{Zn}$, (e) $\mathrm{Al}-30 \mathrm{Zn}$, (f) $\mathrm{Al}-40 \mathrm{Zn}$ ve (g) $\mathrm{Al}-50 \mathrm{Zn}$ alaşımlarına ait X-1şını difraksiyon deseni 
$\mathrm{Bu}$ durum, difüzyon mekanizmasina dayandırılarak açıklanabilir. Şöyle ki; $\alpha$ katı çözeltisi içinde bulunan çinko atomlarının bu katı çözeltiden ayrılıp $\eta$ fazını oluşturabilmeleri ancak difüzyon ile mümkündür. Difüzyon mekanizmasının gerçekleşmesinin ise zaman ve konsantrasyona bağlı olduğu bilinmektedir (Avner, 1997; Savaşkan, 2017). Uygulanan çalışma koşullarında döküm sonrası soğumanın denge şartları dışında (hızlı) olması ve Al-(5-15)Zn alaşımlarındaki çinko konsantrasyonun bu soğuma hızında difüzyon için yeterli olmaması nedeniyle $\eta$ fazı oluşmamış olabilir. Çinko oranının \%15'i aşması durumunda $\eta$ fazının çökelmeye başlaması ve bu orandan sonra artan çinko oranı ile içyapıdaki $\eta$ fazının hacimsel oranının artması hem faz dönüşümlerinin daha yüksek sicaklıklarda gerçekleşmesi hem de $\alpha$ fazı içerisinde çözünmüş durumda bulunan çinko konsantrasyonun daha yüksek olması nedeniyle $\eta$ fazının oluşması için gerekli difüzyon mekanizmasının kolaylaşmasından kaynaklanmış olabilir.

İncelen alaşımların yoğunluk, sertlik ve basma dayanımı değerlerinin çinko oranına göre değişimini gösteren eğriler Şekil 6'da, çekme mukavemeti, kopma uzaması ve özgül mukavemet değerlerinin çinko oranına göre değişimini gösteren eğriler ise Şekil 7'de verilmiştir.

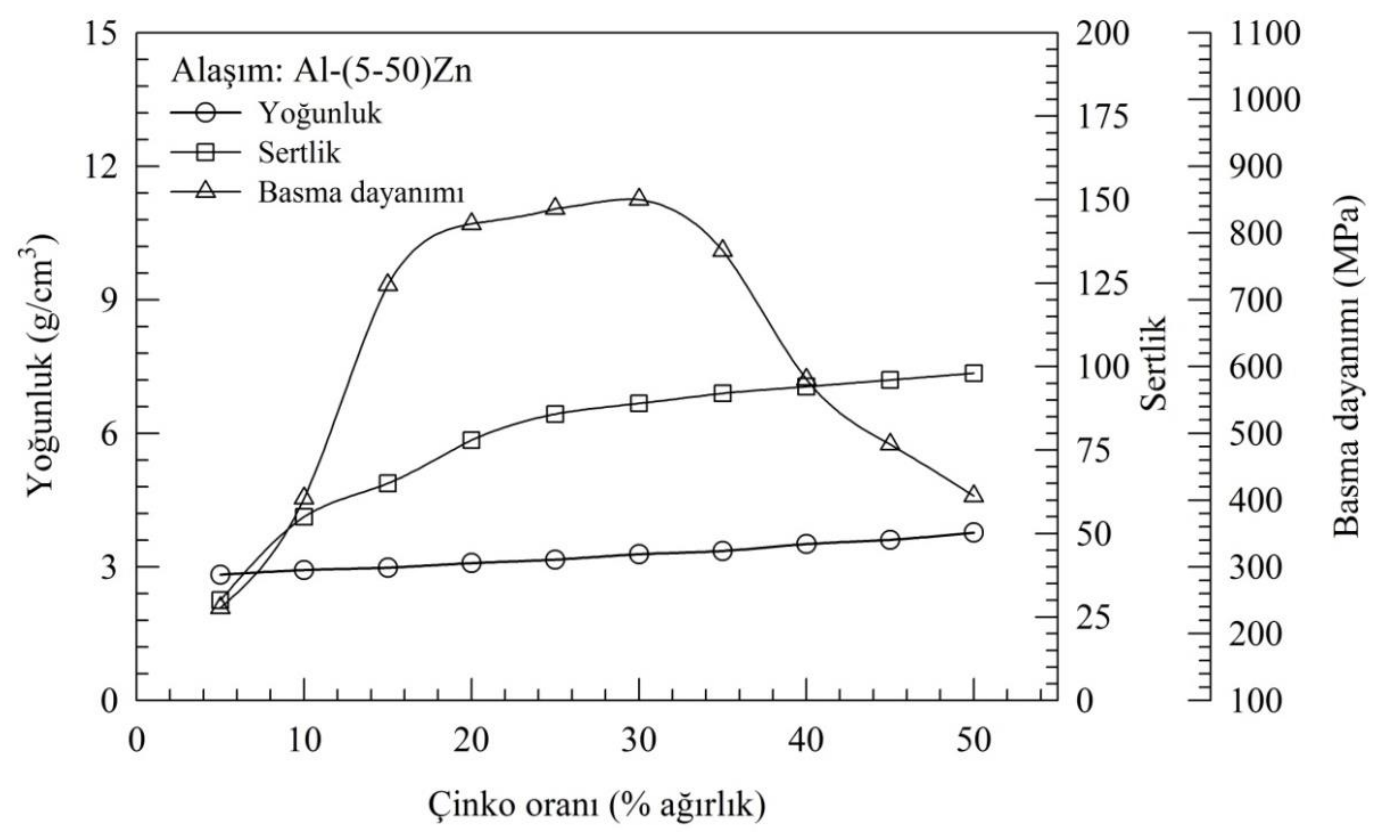

Şekil 6. Al-(5-50)Zn alaşımlarının yoğunluk, sertlik ve basma dayanımı değerlerinin çinko oranına göre değişimini gösteren eğriler

İkili Al-(5-50)Zn alaşımlarının yoğunluk ve sertliğinin artan çinko oranı ile arttığı, basma dayanımı değerinin ise $\% 30$ çinko oranına kadar arttığ $\breve{1}$ bu orandan sonra ise azaldığ 1 görülmektedir (Şekil 6). Söz konusu alaşımların çekme mukavemeti değerlerinin de basma mukavemetine benzer olarak \%30 çinko oranına kadar arttığı, bu orandan sonra ise azaldı $\breve{g}$, kopma uzaması değerlerinin ise artan çinko oranı sürekli azaldığ 1 görüldü (Şekil 7). Alaşımların yoğunluğunun çinko oranı arttıkça artması çinkonun yoğunluğunun alüminyumdan daha yüksek olmasından kaynaklanmaktadır. Artan çinko oranının alaşımların sertlik, çekme ve basma mukavemeti değerlerinde yol açtığı değişimler ise katı çözelti sertleşmesi ve ikincil faz çökelmesi mekanizmalarına dayandırılarak açıklanabilir.
Şöyle ki, içyapı görüntülerinden de anlaşılacağı üzere $\mathrm{Al}-\mathrm{Zn}$ alaşımları \% 15 çinko oranına kadar tek fazlı $(\alpha)$ bir yapıya sahiptir. Al-(5-15)Zn alaşımlarının içyapısında bulunan çinkonun $\alpha$ fazında çözünmüş olması nedeniyle bu fazın kafes yapısında bir çarpılmanın olması beklenir. Kafes yapısının çarpılması bir başka deyişle distorsiyona uğraması dislokasyonların ilerlemesine engel teşkil edeceği için alaşımın sertlik ve mukavemetinde artışa yol açar (Avner, 1997; Abbaschian vd., 2008). Alaşımların sertlik, çekme ve basma mukavemeti \%30 oranına kadar artmış, ancak \%15 çinko oranından sonra bu artışın oranı azalmıştır, Şekil 6 ve 7. Bu durum ise katı çözelti sertleşmesi etkisinin yanı sıra ikincil faz çökelmesinden kaynaklanmış olabilir. Şöyle ki, alaşımların içyapısında ikinci faz $(\eta)$ oluşmasının 
(çökelmesinin) matriste sebep olduğu bölgesel gerilmelerin sertlik ve mukavemet artışına yol açtığı bilinmektedir (Avner, 1997; Abbaschian vd., 2008). Çinko oranının \%30'u aşması durumunda çekme ve basma mukavemeti değerlerinde meydana gelen azalma ise $\alpha$ fazını çevreleyen nispeten gevrek özellikteki çinkoca zengin $\eta$ fazının içyapıdaki hacimsel oranının artmasından ve bu nedenle taneler arasindaki bağların zayıflamasından kaynaklanmış olabilir. Zira, taneler ve/veya dendritler arasındaki mesafenin artması ve/veya taneler arasında gevrek bir ağ olması durumunda alaşımların mukavemet değerlerinde azalmanın meydana geldiği bilinmektedir (Mondolfo, 1976; Tien, ve Ansell, 1976; Bishop ve Smallman, 1999; Miannay vd., 2000; Savaşkan ve Hekimoğlu, 2014b; Rana ve Singh, 2016; Allameh ve Emamy, 2017).

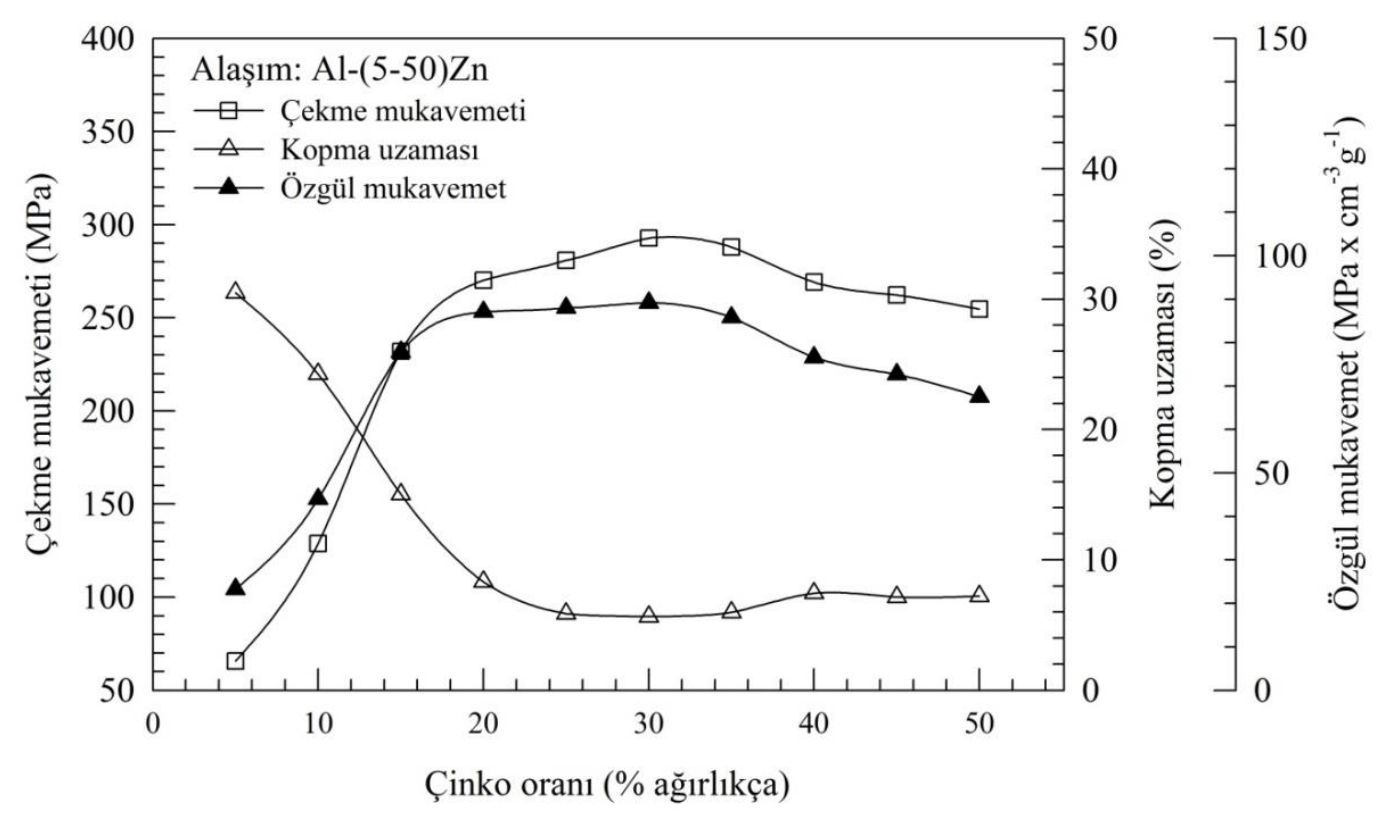

Şekil 7. Al-(5-50)Zn alaşımlarının çekme mukavemeti, kopma uzaması ve özgül mukavemet değerlerinin çinko oranına göre değişimini gösteren eğriler

İncelenen alaşımların özgül mukavemet değerlerinin \%20 çinko oranına kadar önemli bir artış sergilediği, \%20-30 çinko aralığında önemli bir değişiklik sergilemediği, ancak \%30 oranından sonra azaldı̆̆ görüldü (Şekil 7). Artan çinko oranı ile özgül mukavemet değerinde meydana gelen artış alaşımların çekme mukavemeti değerlerindeki artışın yoğunluğundaki artıştan daha fazla olmasından, azalma ise yoğunluk değerlerinin artarken çekme mukavemeti değerlerinin değişmemesinden veya azalmasından kaynaklanmaktadır. \%20-30 çinko aralığında alaşımların özgül mukavemet değerlerinde önemli bir değişim olmaması ise çekme mukavemetlerindeki meydana gelen değişimin yoğunluk değerlerinde meydana gelen değişim ile dengelenmesinden kaynaklanmaktadır.

\section{Sonuçlar}

$\mathrm{Bu}$ çalışmadan elde edilen sonuçlar aşağıda sıralanmıştır:
1. $\mathrm{Al}-(5-15) \mathrm{Zn}$ alaşımlarının içyapısı çinkonun alüminyum içerisinde katı durumda çözünmesiyle oluşan $\alpha$ fazından (katı çözeltisinden) oluşmaktadır.

2. Al-Zn alaşımlarında çinko oranının $\% 15$ 'i aşması durumunda taneler arası bölgelerde $\eta$ fazı oluşmakta ve artan çinko oranı ile $\eta$ fazının içyapıdaki hacimsel oranı artmaktadır.

3. Al-(5-50)Zn alaşımlarında artan çinko oranı ile yoğunluk ve sertlik artmaktadır. Çekme ve basma dayanımı değerleri ise \%30 çinko oranına kadar artmakta, bu orandan sonra ise azalmaktadır.

4. $\mathrm{Al}-20 \mathrm{Zn}, \mathrm{Al}-25 \mathrm{Zn}$ ve $\mathrm{Al}-30 \mathrm{Zn}$ alaşımları birbirine yakın özgül mukavemet değerlerine sahiptir. 


\section{Teşekkür}

Bu çalışma Türkiye Bilimsel ve Teknik Araştırma Kurumu (TÜBİTAK) 2209-A Üniversite Öğrencileri Araştırma Projeleri Destekleme Programı Kapsamında desteklenmiştir (Proje No: 1919B011502999).

\section{Kaynaklar}

Abbaschian, R., Abbaschian, L. ve Reed-Hill, R.E., 2008. Physical Metallurgy Principles, Cengage Learning, Stanford.

Alemdağ, Y. ve Beder, M., 2014. Microstructural, mechanical and tribological properties of Al-7Si-(0-5) $\mathrm{Zn}$ alloys, Materials and Design, 63, 159-167.

Alemdağ, Y. ve Beder, M., 2015. Dry Sliding Wear Properties of Al-7Si-4Zn-(0-5) Cu Alloys. Journal of The Balkan Tribological Association, 21(1), 154-165.

Alhawari, K.S., Omar, M.Z., Ghazalı, M.J., Salleh, M.S. ve Mohammed, M.N., 2017. Microstructural evolution during semi solid processing of $\mathrm{Al}-\mathrm{Si}-\mathrm{Cu}$ alloy with different $\mathrm{Mg}$ contents. Transactions of Nonferrous Metals Society of China, 27, 1483-1497.

Allameh, S.H. ve Emamy, M., 2017. The Effect of Ca Content on the Microstructure, Hardness and Tensile Properties of AZ81 Mg Cast Alloy. Journal of Materials Engineering and Performance, 26(5), 2151-2161.

Altenpohl, D.G., 1998. Aluminum Technology, Applications, and Environment. The Aluminum Association Inc. and TMS, Washington.

ASM International Handbook Committee, 1992. Properties and selection: nonferrous alloys and special purpose materials. ASM International, Materials Park, $\mathrm{OH}$.

Auer, H. ve Mann, K.E., 1936. Magnetic Investigation of Zinc Aluminum System. Zeitschrift für Metallkunde, 28 (10), 323326.

Avner, S.H., 1997, Introduction to physical metallurgy. McGraw Hill, India,

Bayraktar, Ş., Hekimoğlu A.P., Turgut Y. ve Haciosmanoğlu M., 2017a. Effect of
Different Cutting Tools on Machinability of The Al-5Zn Alloy. $2^{\text {th }}$ International Symposium on Industrial Design Engineering-ISIDE, 13-15 Eylül 2017, Nevşehir, Türkiye, s.134-137.

Bayraktar, Ş., Hekimoğlu A.P., Turgut Y. ve Haciosmanoğlu M., 2017b. A Performance Comparison Study of Uncoated and TiAlN Coated Carbide End Mill on Machining of the Al-35Zn Alloy. $9^{\text {th }}$ International Conference on Tribology (BalkanTRib'17), 13-15 Eylül 2017, Nevşehir, Türkiye, s.490-496.

Bishop, R.J. ve Smallman, R.E., 1999. Modern Physical Metallurgy and Materials Engineering, Butterworth-Heinemann, Oxford.

Dursun T. ve Soutis C., 2014. Recent developments in advanced aircraft aluminium alloys. Materials and Design, $56,862-871$.

Gervais, E., Barnhurst, R.J. ve Loong, C.A., 1985. An Analysis of Selected Properties of ZA Alloys. Journal of Metals, 37 (11), 43-47.

Hatch, J.E., 1984. Aluminum: Properties and Physical Metallurgy. American Society for Metals, Ohio.

Kaufman, J.G. ve Rooy, E.L., 2004. Aluminum Alloy Castings: Properties, Processes, and Applications, ASM International.

Kuznetsov, G.M., Barsukov, A.D. ve Krivosheeva, G.B., 1986. Calculation of Phase Equilibria of The Al-Zn System. Russian Metallurgy, 5, 195-198.

Lee, B.H., Kim, S.H., Park, J.H., Kim, H.W. ve Lee, J.C., 2016. Role of $\mathrm{Mg}$ in simultaneously improving the strength and ductility of $\mathrm{Al}-\mathrm{Mg}$ alloys. Materials Science \& Engineering A, 657, 115-122.

Lloyd, D.J., 2003. The scaling of the tensile ductile fracture strain with yield strength in Al alloys. Scripta Materialia, 48 (4), 341344.

Miannay, D., Costa, P., François, D. ve Pineau, A., 2000. Advances in Mechanical Behaviour, Plasticity and Damage. Elsevier Science Ltd., Oxford. 
Mondolfo, L.F., 1976. Aluminum Alloys: Structure and Properties, Butterworth \& Co Publishers Ltd., London.

Murthy, V.S.R., 2003. Structure and Properties of Engineering Materials, McGraw-Hill Publishing Company Limited, Yeni Delhi.

Presnyakov, A.A., Gorban, Y.A. ve Chrevyakova V.V., 1961. The Aluminum-Zinc Phase Diagram. Journal of Physical Chemistry, 35, 632-633.

Rana, R. ve Singh, S. B., 2016. Automotive Steels: Design, Metallurgy, Processing and Applications, Woodhead Publishing, London.

Remøea, M.S., Marthinsena, K., Westermanna, I., Pedersenb, K., Røysetc, J. ve Marioarab, C., 2017. The effect of alloying elements on the ductility of $\mathrm{Al}-\mathrm{Mg}-\mathrm{Si}$ alloys. Materials Science \& Engineering A, 693, 60-72.

Savaşkan, T. ve Hekimoğlu, A.P., 2014a. Microstructure and mechanical properties of Zn-15Al-based ternary and quaternary alloys. Materials Science \& Engineering A, 603, 52-57.

Savaşkan, T. ve Hekimoğlu, A.P., 2014b. Structure and mechanical properties of $\mathrm{Zn}$ (5-25) Al alloys. International Journal of Materials Research, 105(11), 1084-1089.

Savaşkan, T. ve Hekimoğlu, A.P., 2016. Relationships between mechanical and tribological properties of $\mathrm{Zn}-15 \mathrm{Al}$-based ternary and quaternary alloys. International Journal of Materials Research, 107(7), 646652.

Savaşkan, T., 2017. Malzeme Bilimi ve Malzeme Muayenesi: Papatya Yayınevi, İstanbul.
Savaşkan, T., Bican, O. ve Alemdağ, Y., 2009. Developing aluminium-zinc-based a new alloy for tribological applications. Journal of Materials Science, 44(8), 1969-1976.

Savaşkan, T., Hekimoğlu, A.P. ve Pürçek, G., 2004. Effect of copper content on the mechanical and sliding wear properties of monotectoid-based zinc-aluminium-copper alloys. Tribology International, 37(1), 4550 .

Savaşkan, T., Pürçek, G. ve Hekimoğlu, A.P., 2003. Effect of copper content on the mechanical and tribological properties of ZnAl27-based alloys. Tribology Letters, 15(3), 257-263.

Savaşkan, T., Torul, O. ve Çuvalcı, H., 1988. Çinko-alüminyum alaşımlarının içyapı ve mekanik özelliklerinin incelenmesi, 5. Metalurji Kongresi, Kasim 1988, Ankara, Türkiye, s.784-799.

Shabestari, S.G. ve Moemeni, H., 2004. Effect of copper and solidification conditions on the microstructure and mechanical properties of Al-Si-Mg alloys. Journal of Materials Processing Technology, 153-154, 193-198.

Tien, J. ve Ansell, G. S., 1976. Alloy and Microstructural Design, Academic Press, London.

Valiev, R.Z., Alexandrov, I.V., Zhu, Y.T. ve Lowe, T.C., 2002. Paradox of strength and ductility in metals processed by severe plastic deformation. Journal of Materials, 17(1), 5-8.

Wanga, X., Guob, M., Zhangb J. ve Zhuangb L., 2016. Effect of $\mathrm{Zn}$ addition on the microstructure, texture evolution and mechanical properties of $\mathrm{Al}-\mathrm{Mg}-\mathrm{Si}-\mathrm{Cu}$ alloys. Materials Science \& Engineering A, 677, 522-533. 